Proceedings of SALT 28: 000-000, 2018

\title{
Towards a New Explanation of Sequence of Tense*
}

\author{
Carina Kauf \\ University of Goettingen
}

\author{
Hedde Zeijlstra \\ University of Goettingen
}

\begin{abstract}
Past-under-past embeddings have two readings, a simultaneous and a backward-shifted one. While existing accounts derive these readings via distinct mechanisms, be it by means of an ambiguity at the level of LF or via blocking of a cessation implicature, we propose an alternative account which avoids such ambiguity. For us, the meaning of a past tense morpheme, like -ed, is comprised of two components. Syntactically, every past tense morpheme carries an uninterpretable past feature [uPAST], to be checked by a (single) covert past tense operator $O p$ $P A S T$ carrying an interpretable feature [iPAST]. Semantically, the past tense marker encodes a relative non-future with respect to its closest c-commanding tense node (informally: 'not later than'), immediately yielding the two distinct readings.
\end{abstract}

Keywords: Sequence of tense / Past-tense morphology / Tense / Embeddings / Ambiguity / Double-access reading / Syntax-semantics interface

\section{Introduction}

Sentences in which a past tense is embedded under a matrix past have two readings: a simultaneous ( $\operatorname{sim}$ ) and a backward-shifted (b-s) one.

(1) John said Mary was ill.

a. John, at some $t^{\prime}<$ utterance time, $t_{u}$ : "Mary is ill."

b. John, at some $t^{\prime}<t_{u}$ : "Mary was ill."

The availability of the sim reading for past-under-past constructions - commonly referred to as Sequence of Tense (SoT) - has been a prevalent topic of research for several years. This is because, intuitively, there is two ways to think about past tense, and both of them fail to predict the two-fold meaning distinction observed in (1): Under an absolute view on past tense, each instance of past tense is taken to

* We thank the audiences of GLOW 41, SALT 28, B1-Vortragsreihe Tübingen and the Amsterdam Colloquium 2017 for insightful questions and discussion, as well as Daniel Altshuler, Dorit Abusch, Yael Sharvit, Cleo Condoravdi, Vera Hohaus, Sigrid Beck, and Tim Stowell for personal comments. All errors are, of course, our own. This research is part of the DFG project Past Tense Morphology in Tense and Modality (DFG ZE 1040/2).

C2018 Kauf, Zeijlstra 
place the event time of the predicate it scopes over prior to the sentence's utterance time. In clauses in which a past tense morpheme is embedded under a matrix past, two such prior-to- $t_{u}$ relations are established, without further specifying the internal order of the two past events. While such a view correctly predicts the sim and the b-s reading for past-under-past sentences, it also, incorrectly, predicts the availability of a forward-shifted (f-s) interpretation, i.e. one in which the time of John's saying precedes the time of Mary's being ill. The second intuitive way to look at past tense is to regard it as a relative tense. Under such a view, each instance of past tense is assumed to place the event time of the predicate it scopes over prior to the predicate's local evaluation time, which is provided by its closest c-commanding tense, or, in the absence of such a tense, by the utterance time. A relative view on past tense correctly rules out a f-s interpretation of (1) (since the matrix tense provides the local evaluation time of the embedded tense), but at the same time fails to predict the availability of the sim reading. The only reading it (correctly) predicts is the b-s one. Hence, neither of the two intuitive views on past tense correctly predicts the two-fold meaning distinction of (1).

As a result, all existing accounts of SoT derive the sim and the b-s readings of past-under-past sentences via distinct mechanisms. Most implement the distinction as an ambiguity at the level of LF, assuming either a syntactic rule of tense deletion under certain conditions (Ogihara 1995; von Stechow 1995), a zero tense in the embedded clause (Kratzer 1998), a feature transfer mechanism that transmits temporal relations (Abusch 1997), or a combination of the last two (Grønn \& von Stechow 2010), among others. However, the systematic, cross-linguistic availability of this ambiguity casts doubt on whether it should indeed be attributed to two different LFs, instead of receiving a more principled explanation. A different type of proposal assumes the ambiguity to take place at a higher level - pragmatics - and derives the two distinctive readings on the grounds of the blocking/existence of a cessation implicature (Altshuler 2016; Altshuler \& Schwarzschild 2012).

\section{Proposal}

In this paper, we propose an alternative approach for SoT that avoids this ambiguity. For us, the meaning of a past tense morpheme, like -ed, is comprised of two components. In line with many others (e.g. von Stechow 2003; Stowell 2007; Zeijlstra 2012) we assume that, syntactically, each past tense morpheme carries an uninterpretable past feature [UPAST], to be checked by a covert past tense operator $O p$-PAST that carries the according interpretable feature [iPAST]. (In this paper we restrict ourselves to temporal interpretations of past tense morphology, taking non-past, non-factual readings of past tense morphology out of consideration.) We implement this past tense operator in the following way: 
Towards a New Explanation of Sequence of Tense

$$
\llbracket O p-P A S T \rrbracket=\left[\lambda t^{*} . \lambda P . \exists t<t^{*} \& P(t)\right]
$$

At matrix level, $t^{*}$ in principle applies to $t_{u}$ and for the sake of easiness we will take $O p$-PAST to denote [ $\lambda P . \exists t<t_{u} \& P(t)$ ] in these cases. Nevertheless, later in this paper we will discuss examples in which the value deviates from the default, providing evidence for the necessity of the more complex definition of the operator given in (2).

That past tense takes higher scope than the surface position of the past tense marker has been well-established in the literature (Klein 1994; Ogihara 1996; Abusch 1997; von Stechow 2002; Zeijlstra 2012). Evidence for this comes from examples like:

(3) Wolfgang played tennis on every Sunday.

(von Stechow 2006)

The interpretation of (3) is one in which past tense outscopes the distributive quantifier every Sunday, yielding the paraphrase in (4a). If the scopal order is reversed, the only possible interpretations are (4b) and (4c), both of which are infeasible (cf. Zeijlstra 2012; von Stechow 2002, 2005).

(4) (In)feasible paraphrases of (3) as the result of different scopal orderings

a. = 'For every Sunday in the past, there is a time $t$ at which Wolfgang plays tennis.'

b. $\neq$ 'There is past time on every Sunday at which Wolfgang plays tennis.'

c. $\neq$ 'For every Sunday, there is time before it such that Wolfgang plays tennis at that time.'

Even though the locus of past tense is different from its overt instantiation, i.e. the tense marker - $e d$, this does not entail that the past tense morpheme is semantically vacuous. In fact, our approach deviates from existing agreement accounts in assuming that both the covert operator and the past tense morpheme are semantically active. We argue that the tense marker encodes a relative non-future semantics with respect to its closest c-commanding tense node (informally: 'not later than') (cf. Kratzer 1998; von Stechow 2003). Accordingly, it has the following denotation:

$$
\llbracket \text {-ed } \rrbracket=\left[\lambda t . \lambda P . \exists t^{\prime} . t^{\prime} \leq t \& P\left(t^{\prime}\right)\right]
$$

In this context, the expression $t^{\prime} \leq t$ is defined to mean that the lower boundary of the time interval $t^{\prime}$ is not later than the lower boundary of the time interval $t$. Hence, an event happening at time $t^{\prime}$ starts either strictly earlier than or at the same time as an event happening at time $t$, but can never start after it.

A simple sentence such as Susan left thus receives the subsequent interpretation: 
(6) Susan left.

a. [ $O p-P A S T_{[\mathrm{iPAST}]}[$ Susan leave-ed $[\mathrm{uPAST}]]$

$$
\exists t^{\prime}<t_{u} \quad \exists t^{2} \leq t^{\prime}
$$

b. $\exists t^{\prime}<t_{u} \&\left[\exists t^{2} \leq t^{\prime} \&\right.$ leave(Susan, $\left.\left.t^{2}\right)\right]$

c. There is a time $t^{\prime}$ strictly before the utterance time $t_{u}$ and Susan leaves at a time no later than $t^{\prime}$.

The analysis deviates from standard analyses in that it introduces an ambiguity with respect to the ordering of $t^{\prime}$ and $t^{2}$ : They either refer to the same point in time or the latter precedes the former. If $t^{\prime}$ and $t^{2}$ are taken to refer to the same point in time, the most prominent interpretation of the sentence, i.e. a simple past reading (Susan left at a time prior to $t_{u}$ ), is derived. Nevertheless, there are contexts in which a speaker may choose to use a (simple) past-tensed sentence even though the interpretation he wants to trigger is actually more comparable to a past perfect one:

a. Did Susan go to today's 4pm class?

\section{b. No, she left for Spain.}

The intended interpretation of (7b) is one that places Susan's leaving for Spain prior to 4pm today (cf. reference time in Reichenbach 1947). Most likely due to pragmatic blocking effects, this ambiguity of past tense usually remains unnoted in unembedded sentences as the same information can - more transparently - be expressed via a past-perfect construction.

Whereas the 'not later than'-ambiguity yielded by the semantic meaning component of past tense morphology (i.e., (5)) does not usually change the meaning of unembedded sentences, it directly entails that every past tense embedded under another past tense is ambiguous between a simultaneous and a backward-shifted reading. This becomes evident from the hierarchy of the tense nodes our proposal yields for such cases: The absolute past tense operator places the sentence prior to the utterance time, thus providing the temporal head of the time chain; all other past tense nodes semantically express a relative non-future with respect to their closest c-commanding tense node. In cases where $O p$-PAST can check all [uPAST] features via multiple agree, this configuration yields a totally ordered set of tense nodes from the matrix past operator to the most embedded past tense node. For an illustration of our proposal, consider the following derivation (where we take say to be an extensional predicate):

John said Mary was ill.
a. [ $O p-P A S T_{[\mathrm{iPAST}]}$ $\exists t^{\prime}<t_{u}$
John
say-ed [uPAST] $\exists t^{2} \leq t^{\prime}$
[ Mary [ be- $\exists t^{3} \leq t^{2}$ ill.]1]]] 
Towards a New Explanation of Sequence of Tense

b. $\exists t^{\prime}<t_{u} \&\left[\exists t^{2} \leq t^{\prime} \& \operatorname{say}\left(\mathrm{John}, t^{2},\left[\exists t^{3} \leq t^{2} \&\right.\right.\right.$ be-ill(Mary, $\left.\left.\left.\left.t^{3}\right)\right]\right)\right]$

c. John's saying is strictly before the utterance time $t_{u}$ and Mary's being ill starts out no later than the time as John's saying.

The covert past tense operator in (8) places the proposition at some time $t^{\prime}<t_{u}$. Since both of the embedded past tenses lie within the syntactic domain of this higher operator, it can check both morphemes' [UPAST] features via multiple agree. This gives rise to the following semantic relations: The two past tense morphemes each introduce a relation of a relative non-future with respect to their closest ccommanding tense node. Hence, $t^{2}$ is interpreted as a relative non-future with respect to $t^{\prime}$, and $t^{3}$ constitutes a relative non-future with respect to $t^{2}$. The backward-shifted reading of (8) then arises in case that $t^{3}<t^{2}$, while the simultaneous interpretation is yielded for $t^{3}=t^{2}$.

One may wonder why a second $O p$-PAST operator may not have been included in the embedded clause to check off the lower past tense morpheme's [uPAST] feature. Zeijlstra (2012) proposes that the number of operators is regulated by economy principles: A second operator may only be included when necessary. Since the covert past tense operator in (2) can check all of the uninterpretable past tense features in its syntactic domain (via multiple agree), multiple past tense morphemes in principle require the presence of only one past tense operator. With respect to Zeijlstra's economy constraint, this means that when one $O p$-PAST can check all present [UPAST] features, no further $O P$-PAST may be included.

\section{Explaining Challenging Past-Under-Past Embeddings}

The previous section has shown that for standard SoT sentences, our theory yields the correct results: it derives the simultaneous and the backward-shifted reading in pastunder-past embeddings, but crucially not the forward-shifted reading. Nevertheless, in principle, any theory of SoT also has to account for more complex cases of temporal embeddings, e.g. cases in which an embedded past tense refers to a time in the future, or in which a past tense is not even ordered relatively to a higher tense node. This section is devoted to showing how our approach deals with such challenging SoT sentences.

\subsection{Complement Clausal Embeddings}

\subsubsection{Future Reference in Past-Under-Past Embeddings - Embedded Past}

The following examples show that a past-embedded past tense can make reference to a time interval that lies strictly after the time of utterance: 
(9) He said he would buy a fish that was still alive.

(Ogihara 1989)

(10) He decided a week ago that in ten days he would say to his mother that they were having their last meal together.

(Abusch 1988)

The challenge comes from the interpretation of their most embedded past tense forms (underlined in the above examples). As has been well-established in the literature (cf., e.g., Abusch 1997; Ogihara 1995) the most prominent reading of these past tense morphemes is one of simultaneity with respect to their c-commanding tense nodes, which, in these examples, have been shifted to a time later than the matrix time by means of the modal would. In (9) a past tense can thus be used to describe the state of a fish's being alive, even if this time interval lies in the strict future of the utterance time. In (10), past tense morphology is used to describe a containment relation between the time of the saying event (which is necessarily interpreted as being later than the matrix time due to the overt modifying clauses) and the event time of the last meal. In this example, it is further the case that the backward-shifted relation between the most embedded past tense and its ccommanding tense node that our analysis predicts to be available is independently blocked due to additional aspectual information (i.e. the imperfective aspect on having); hence, this does not provide a problem for the proposed analysis.

Our approach successfully captures the multiple interpretations of such 'fishsentences' under the assumption that would is a combination of the operator woll (a tense operator that places the evaluation time of a proposition in the relative future of the sentence's current evaluation time) plus a [UPAST] feature that restricts it to past tense sentences (again taking non-past, non-factual readings of would out of consideration here).

$$
\llbracket \operatorname{woll}_{[\mathrm{uPAST}]} \rrbracket=\left[\lambda t . \lambda P . \exists t^{\prime} . t^{\prime}>t \& P\left(t^{\prime}\right)\right]^{1}
$$

We assume that would does not carry complete past tense morphology, which is why it does not introduce a relative-non future relation with respect to its closest c-commanding tense node. Our proposal would, however, not be affected if would were to contain such an underlying morpheme.

(12) John said he would buy a fish that was alive.

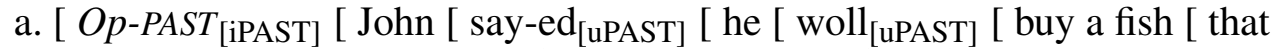

$$
\begin{aligned}
& \exists t^{\prime}<t_{u} \quad \exists t^{2} \leq t^{\prime} \quad \exists t^{3}>t^{2} \\
& \text { be-ed [uPAST] alive.]]]]]]] } \\
& \exists t^{4} \leq t^{3}
\end{aligned}
$$

1 Here, we ignore the modal contribution of the operator woll in terms of universal quantification over possible worlds (cf. e.g. Ippolito (2013)), which is orthogonal to the analysis presented in this paper. 
Towards a New Explanation of Sequence of Tense

b. $\exists x\left[\operatorname{fish}(x) \& \exists t^{\prime}<t_{u} \cdot \exists t^{2} \leq t^{\prime}\right.$ : say(John, $t^{2},\left[\exists t^{3}>t^{2}\right.$ : buy(he, $\left.t^{3}, x\right) \&$ $\left.\left.\left.\exists t^{4} \leq t^{3}: \operatorname{alive}\left(x, t^{4}\right)\right]\right)\right]$

c. There is a time $t^{4}$ which is the time of a contextually salient fish's being alive, and $t^{4}$ is prior or equal to some time $t^{3}$. The time $t^{3}$ is the time of John's buying the fish which lies strictly after $t^{2}$, i.e. the time of John's saying event. $t^{2}$ is prior or equal to $t^{\prime}$ which, in turn, is a time strictly before the utterance time $t_{u}$.

What is essential about the analysis is that the most embedded past, i.e. was in (12), is ordered prior or equal to the time of the buying, and not prior to any other time, such as the matrix time or the utterance time. This correctly yields a later-than-matrix interpretation of the embedded past tense. The simultaneous and the backward-shifted reading of sentence (12) can be made evident via adding suitable modifying clauses:

(13) The two readings of (12):

a. Backward-shifted interpretation

John said (three days ago) that (in ten days) he would buy a fish that was alive (a day before/two weeks before).

\section{b. Simultaneous interpretation}

John said (three days ago) that (in ten days) he would buy a fish that was (still) alive (then).

Similarly, the same applies to example (10). Even when neglecting the temporal modifying clauses, which indubitably place the time of the meal in the future, the formula derived from the tense nodes within the sentence already shows that the time of the meal is not restricted to a past interval. As it is ordered relatively to the future-shifted time of the saying event, the time of the meal can lie strictly after $t_{u}$.

\subsubsection{Future Reference in Past-Under-Past Embeddings - Matrix Past}

Another set of challenging data which invokes a future reference for a past-embedded past tense in a complement sentence is comprised of sentences like the following:

(14) He hoped she tried to kill him first.

(Klecha 2016)

The novel challenge posed by these examples lies in the fact that they have an interpretation akin to that of (9) and (10), even though they do not contain an overt future shifter, like woll. Klecha (2016) argues that the availability of such an independent future-shifted interpretation is restricted to predicates that already have an inherent modal future orientation built into their semantics, such as hope or 
pray. Such modals deviate from other, non-future-oriented predicates like think in the modal bases they may combine with. While think, e.g., may only combine with a doxastic modal base, hope may combine with either a doxastic or a circumstantial modal base (cf. Klecha 2016: 18). Klecha argues that predicates which take an epistemic, doxastic or reportative modal base impose an upper limit, i.e. do not allow a future-orientated interpretation, whereas predicates which take a deontic, bouletic or teleological modal base do not (cf. Klecha 2016: 6).

Such a view is in accordance with our proposal; even though the past tense morphology on hope in (14) places the time of the matrix sentence prior to the utterance time, as a future-oriented predicate, hope by itself can shift the evaluation time of its complement proposition to a future point in time - even in the absence of the modal woll.

(15) He hoped she tried to kill him first.

$$
\begin{aligned}
& \text { a. [Op-PAST }{ }_{[\mathrm{iPAST}]}\left[\mathrm{He} \text { [ hope }-\mathrm{ed}_{[\mathrm{uPAST}]}\left[\operatorname{she~try-ed~}_{[\mathrm{uPAST}]}[\text { to kill him }\right.\right. \\
& \exists t^{\prime}<t_{u} \quad \exists t^{3} \geq t^{2} \quad \exists t^{2} \leq t^{\prime} \quad \exists t^{4} \leq t^{3} \\
& \text { first ]]]]] }
\end{aligned}
$$

In our proposal, this inherent future-orientation of hope is hard-wired into its semantics in an operational manner; nevertheless, we are not dependent on this implementation of Klecha's insight. Any type of inherent future semantics as part of the lexical meaning of such predicates can derive these facts under our analysis.

As a result of the inherent future shift, our analysis derives the correct meaning of such future-shifted sentences mutatis mutandis: Since the forward-shifted evaluation time $t^{3}$ is introduced in the matrix clause (which can lie strictly after the time of utterance $t_{u}$ ), the verb tried then simply means tried at time $t^{4}$, whereby $t^{4}$ is no later than $t^{3}$ and can also lie in the strict future of $t_{u}$.

\subsubsection{Future Reference in Past-Under-Future Embeddings - Embedded Past}

Future-embedded past tenses (cf. (16)) also give rise to a reading in which the pastmarked predicate may take place after the utterance time, and thus pose a further challenge to SoT theories.

Alan will think everyone hid.

Since the modal woll is instantiated as will in this case, it becomes immediately evident that the $O p$-PAST cannot take higher scope than the modal (as otherwise it would be spelled out as would). Hence, the underlying structure of (16) must be the following (cf. also Heim 1994):

[ will think [ $O p-P A S T_{[\mathrm{iPAST}]}\left[\right.$ everyone hide-ed $\left.\left._{[\mathrm{uPAST}]}\right]\right]$ 
Towards a New Explanation of Sequence of Tense

The semantics of will is given by the denotation for the modal operator woll as in (11) modulo the [UPAST] feature (see also (31) for more discussion). Sentence (16) does not provide a local evaluation time for woll's relative parameter $t$; as a result, $t$ gets valued by its default value $t_{u}$. Under these assumptions, the correct interpretation of (16) is yielded since will - taking scope over the past tense operator - changes the local evaluation time $t^{*}$ of $O p$-PAST to a time in the future. It is from this future-shifted point in time that $O P$-PAST introduces a no-later-than relation; no direct connection between the event time of the past-tensed predicate and $t_{u}$ is thus established, which is why the hiding can lie in the strict future of $t_{u}$.

Alan will think everyone hid.

a. [ will think [ $O p$-PAST ${ }_{[\mathrm{iPAST}]}[$ everyone hide-ed $[$ [uPAST] $]]$ $\exists t^{\prime}>t_{u} \quad \exists t^{2}<t^{\prime} \quad \exists t^{3} \leq t^{2}$

b. $\exists t^{\prime}>t_{u} \&$ think(Alan, $t^{\prime},\left[\exists t^{2}<t^{\prime} \& \exists t^{3} \leq t^{2} \&\right.$ hide(everyone, $\left.\left.t^{3}\right)\right]$ )

c. There is a time $t^{\prime}$ in the strict future of $t_{u}$ and Alan thinks at $t^{\prime}$ that there is a time $t^{2}$ earlier than $t^{\prime}$ such that everyone from a contextually salient group hid at a point $t^{3}$ no later than $t^{2}$.

Note that if the operator $O p$-PAST entailed an absolute past ordering of the sentence it takes scope over with respect to the utterance time, these cases could not be accounted for by our proposal. However, as seen in (2), the relation 'prior to time of utterance' is not cooked into the semantics of $O p$-PAST; Instead, the operator is defined as a relative past with respect to a time variable $t^{*}$, whose value may be $t_{u}$, but which can also refer to a time interval later than $t_{u}$ if introduced by an independent source, e.g. by the modal operator will (cf. (18)).

\subsection{Relative Clausal Embeddings}

A further set of data where past-under-past morphology exhibits a deviant behavior from the default is comprised of relative clauses: In certain relative clauses as in example (19), the embedded past can yield any of the following readings: a backward-shifted, a simultaneous and a later-than-matrix one.

(19) Mary met a woman who was president.

[non-restr.]

a. In 2000, Mary met a woman who was president in 1995 .

b. In 2000, Mary met a woman who was president in 2000.

c. In 2000, Mary met a woman who was president in 2004.

However, this is not the case for every relative clause. In (20) the later-thanmatrix reading is not available (Heim 1994; Ogihara 1995; Stowell 2007): 
Kauf, Zeijlstra

(20) Mary was looking for a woman who was president.

[restr.]

a. In 2000, Mary was looking for a woman who was president in 1995.

b. In 2000, Mary was looking for a woman who was president in 2000.

c. * In 2000, Mary was looking for a woman who was president in 2004.

Whereas Enç (1987) observed that relative clause tenses differ from complement clause tenses in allowing an independent, or absolute interpretation, Abusch (1988) showed that this only applies to relative clauses that receive a de re interpretation (see also Ogihara 1989, 1996). Indeed in (19), only a de re reading is available. In (20), a de dicto reading is available.

The de relde dicto distinction is strongly connected to the distinction between restrictive and non-restrictive (or appositive) relative clauses, as can also be witnessed in the above examples: (19) contains a non-restrictive and a de re-interpreted relative clause. By contrast, under the triggered de dicto reading of (20), the relative clause is understood to be restrictive. Non-restrictive relative clauses only allow de re interpretations. As is well known, restrictive and non-restrictive relative clauses behave differently with respect to syntactic locality. Whereas non-restrictive relative clauses are syntactically opaque (cf. Safir 1986; Fabb 1990; Demirdache 1991; Borsley 1992; Arnold 2007 for different accounts for the locality effects of nonrestrictive relative clauses), restrictive relative clauses are more accessible. The fact that different types of relative clauses allow for different readings with respect to the availability of forward-shifted readings, opens up a way to think about the availability of the forward-shifted reading in terms of syntactic locality.

In this we follow Stowell (2007) who argues that the de dicto/de re distinction is structurally encoded in terms of the LF position of the relative clause: outside or inside the CP complement of the intensional verb. Concretely, we entertain the hypothesis (in line with Stowell 2007, though also substantially different from it) that the past tense morpheme inside a relative clause that yields a de dicto reading can have its [uPAST] feature checked against a higher covert tense operator carrying [iPAST], but that the past tense morpheme inside a relative clause that yields a de re interpretation cannot do so. Consequently, the latter requires a covert past tense operator of its own, with $t^{*}$ being valued for the time of utterance. Therefore, a relative clause with a de dicto interpretation allows only a simultaneous reading and a backward shift (when containing past tense morphology embedded by a higher past tense clause), whereas a relative clause with a de re interpretation in the same situation yields a simultaneous reading, a backward shift and a forward shift.

This explains why the two past tense markers in $(19) /(21)$ need to be evaluated independently of each other with respect to the time of utterance: Given the syntactic opacity of the (non-restrictive) relative clause, which yields the de re reading, the 
Towards a New Explanation of Sequence of Tense

lower $O p$-PAST in (21) cannot be bound by any higher tense variable, licensing its existence under the economy principle (Zeijlstra 2012).

(21) Mary met a woman who was president.

a. [ $O p-P A S T_{[\mathrm{iPAST}]}\left[\right.$ Mary meet-ed ${ }_{[\mathrm{uPAST}}$ a woman [ who [ $O p-P A S T_{[\mathrm{iPAST}}[\mathrm{l}$

$$
\exists t^{\prime}<t_{u} \quad \exists t^{2} \leq t^{\prime} \quad \exists t^{\prime \prime}<t_{u}
$$

be-ed $[$ [uPAST] president]]]]]

$$
\exists t^{3} \leq t^{\prime \prime}
$$

b. $\exists x\left[\operatorname{woman}(x) \& \exists t^{\prime}<t_{u} . \exists t^{2} \leq t^{\prime}\right.$ : meet(Mary, $\left.x, t^{2}\right) \& \exists t^{\prime \prime}<t_{u} \cdot \exists t^{3} \leq t^{\prime \prime}$ : $\left.\operatorname{president}\left(x, t^{3}\right)\right]$

c. There is a woman $x$ and at $t^{2}$, prior or equal to $t^{\prime}$ which, in turn, is a time strictly before the utterance time $t_{u}$, Mary met $x$, and at $t^{3}$, prior or equal to $t^{\prime \prime}$ which, in turn, is a time strictly before the utterance time $t_{u}, x$ is president.

The relative clause in (22), which is not syntactically opaque and for which agreement inside of the relative clause is therefore possible, yields a temporal interpretation that is similar to that of complement clauses of intensional verbs. The most embedded past tense is ordered with respect to the matrix tense and cannot independently be placed prior to the utterance time:

(22) Mary was looking for a woman who was president.

a. [ $O p-P A S T_{[\mathrm{iPAST}]}\left[\right.$ Mary be-ed ${ }_{\text {[uPAST] }}$ looking for a woman [ who [

$$
\begin{array}{cl}
\exists t^{\prime}<t_{u} & \exists t^{2} \leq t^{\prime} \\
\text { be-ed } & \\
\exists t^{3} \leq t^{2} &
\end{array}
$$

b. $\exists t^{\prime}<t_{u} . \exists t^{2} \leq t^{\prime}$ : be-looking-for(Mary, $t^{2},\left[\exists t^{3} \leq t^{2}\right.$ : $\exists x[\operatorname{woman}(x)$ : be$\left.\left.\left.\operatorname{president}\left(x, t^{3}\right)\right]\right]\right)$

c. At $t^{2}$, prior or equal to $t^{\prime}$ which, in turn, is a time strictly before the utterance time $t_{u}$, Mary is looking for a woman $x$, and at $t^{3}$, prior or equal to $t^{2}, x$ is president.

\section{Advantages of this SoT Approach}

The account proposed in this paper has several advantages over existing approaches. First, we do not have to postulate that there is a difference between a real past and a surface past, which is, in fact, a present tense in disguise (cf., e.g., Ross 1967; Abusch 1988). By defining past as a relative non-future, the proposed approach can account for the same cases as the present-in-disguise proposals while at the same time avoiding unwanted ambiguity and instead retaining a clear 1:1 mapping 
between temporal form and temporal meaning. Further empirical evidence in favor of such an underspecification approach comes from examples like (23), in which a past-tensed clause is used to summarize both a sim and a b-s interpretation of past tense:

Today, John said "Mary is ill," and Bill said "Mary was ill a month ago." Therefore both of them said she was ill (at some point).

Secondly, the proposed SoT account is dependent neither on the intensional/extensional distinction for the embedding predicates (Abusch 1997), nor on the stative/eventive distinction of the past embedded verbs (Altshuler 2016; Altshuler \& Schwarzschild 2012). In her pioneering proposal, Abusch $(1988,1997)$ assumes that feature transmission (leading to the SoT effect) only arises with intensional embeddings - a claim that appears to be too strong. As has been illustrated in (8), the analysis we propose in principle also applies to extensional embeddings, yielding the same SoT effects as for intensional embeddings. Existing pragmatic theories of SoT (Altshuler 2016; Altshuler \& Schwarzschild 2012) on the other hand assume that past-under-past embeddings are not ambiguous between a simultaneous and a backward-shifted reading but that they always have a backward-shifted interpretation. According to their theory, the perception of simultaneity arises in the absence of a cessation implicature, which is computed only when there is competition with a present tense. Such an absence of cessation is only licensed by the temporal profile of stative (and not eventive) predicates (i.e. For any tenseless stative clause $\phi$, if a moment $m$ is in $\llbracket \phi \rrbracket$, then there is a moment $m^{\prime}$ preceding $m$ and a moment $m^{\prime \prime}$ following $m$ such that $m^{\prime}$ and $m^{\prime \prime}$ are in $\llbracket \phi \rrbracket$ ) (Altshuler 2016; Altshuler \& Schwarzschild 2012). Since the absence of cessation is restricted to stative predicates, this type of proposal in principle predicts that past-under-past embedded eventive predicates are always interpreted in a backward-shifted manner, which is the standard assumption. Our proposal, by contrast, in principle allows for sim and b-s readings for both embedded eventive and embedded stative predicates. A possible point of evaluation between the two proposals is therefore provided by the existence or non-existence of simultaneous readings of past-embedded eventive predicates.

That only stative predicates may receive a simultaneous interpretation has, for example, been refuted by Kusumoto (1999). She argues, with Partee (p.c. to Kusumoto, as cited in Khomitsevich 2007), that the examples in (24) have a simultaneous reading even though they embed a past eventive verb:

(24) a. Elliott observed/noticed/perceived that Josephine got hurt.

b. He didn't realize that his car hit the curb.

c. The pilot was sure that the plane landed in the correct spot.

(Kusumoto 1999) 
Towards a New Explanation of Sequence of Tense

This data is not uncontroversial, however. In English, where there exists a grammaticalized imperfective-perfective distinction, the use of perfective aspect in past-under-past constructions yields a preference for a b-s reading. This is because the imperfective grammatical competitor (i.e. Elliott observed that Josephine was getting hurt) unambiguously triggers a sim reading due to its stativity property, and thus provides a more transparent way to express the desired reading. The fact that there are such aspectual competitors in English suggests that the absence of the sim reading in English past-under-past perfectives may be due to pragmatic blocking effects rather than a property of past itself.

Further evidence for this hypothesis comes from languages like Dutch, in which the imperfective-perfective distinction is not grammatically marked. Since there is no designated aspectual operator which requires stativity of the predicate it scopes over, past-under-past constructions may receive a sim reading even when the embedded predicate is an eventive. In fact, the most salient interpretation of a past-embedded past tense for any kind of predicate in Dutch is a simultaneous reading. When wanting to express a b-s interpretation, an embedded past perfect has to be used.

The most salient interpretation for a sentence like (25) is hence one in which Marie witnessed the exact moment in which Hans stabbed Piet, i.e. a sim reading of the embedded past.

$$
\text { Marie zag dat Hans Piet neerstak. }
$$

Marie see-PAST that Hans Piet stab-PAST

[Dutch]

'Marie saw that Hans stabbed Piet.'

Lastly, the account proposed in this paper is built on a number of parameters (e.g. the no-later-than semantics of past tense morphemes, $O p$-PAST being a relative past operator, a.o.), which, taken together, yields our analysis of past-under-past embeddings. The existence of such parameters opens up a space for variation, which in principle should account for cross-linguistic differences attested with respect to SoT: Whereas English-like SoT-languages may for example encode a constraint in order to rule out an unwanted forward shift of default past-under-past clausal embeddings (e.g. Mary's illness in (8) cannot have started later than at $t^{2}$ ) directly as part of their semantics (cf. (5)), non-English-like SoT languages may exhibit different parameter configurations. An example of a language which is, presumably, built on a different parameter setting is Japanese, for which a past-embedded past tense can only yield a backward-shifted reading (cf. e.g. Ogihara 1989, 1996). Hence, at least the semantic contribution of Japanese past morphology differs from that of English. A proper investigation of this hypothesis is part of future research. 
Kauf, Zeijlstra

\section{Extensions to Present Tense}

Another strong suit of the proposal is that it easily extends to embedded present tense, for which a similar ambiguity puzzle can be observed: As embedded PTM, embedded Present-Tense Morphology (PrTM), too, can be interpreted in one of two different ways, depending on the matrix environment (cf. (26)). In (26a), PrTM is embedded under a future-shifted matrix time. This setting leads to a simultaneous (sim) interpretation of the present-tensed complement clause; i.e., one in which the time of Mary's pregnancy is understood to overlap the time of John's saying event which lies in the strict future - but not necessarily the utterance time $t_{u}$. The example (26a) can thus be feasibly paraphrased as follows: John, at some $t>t_{u}$ : "Mary is pregnant (now)." In (26b), by contrast, where PrTM is embedded under a past matrix verb, the present tense is interpreted as fulfilling a different, dual role: It anchors the time of Mary's pregnancy to both the utterance time and the time of John's saying, i.e., its local evaluation time. As a result, (26b) turns out true if and only if Mary is pregnant at $t_{u}$ and Mary is pregnant at some $t<t_{u}$, whereby $t$ denotes the time of John's saying event. Such a reading of PrTM is usually referred to as a double-access $(\mathrm{d}-\mathrm{a})$ reading.
a. John will say Mary is pregnant.
[sim]
b. John said Mary is pregnant.

As with past tense, the established two-way meaning distinction of PrTM poses a puzzle to traditional relative/absolute views on tense (cf., e.g, Ogihara 1995; Abusch 1997; Ogihara \& Sharvit 2012 and references therein for discussion and overview). A relative view on present tense predicts that each instance of PrTM includes its respective local evaluation time; an absolute view on present tense tense proposes that PrTM always establishes an overlapping relation with respect to $t_{u}$. Nevertheless, the above data suggests that neither view can capture the full meaning of present tense: Whereas (26a) provides evidence for a purely relative view on present tense, as no reference to $t_{u}$ is made, the example in (26b) refutes such a view: when embedded under a past matrix verb, present tense always makes reference to $t_{u}$ in addition to to its local evaluation time. (Note that this reflects a similar kind of problem that we identified for past-under-past embeddings.) As a result, a viable proposal for present tense meaning must be more complex.

Even though the ambiguity of PTM has received a lot of attention in the literature, the PrTM-counterpart of the puzzle has been discussed less extensively so far. This might be due to the fact that, prima facie, the cases of PTM- and PrTMunderspecification do not seem directly related, as the two-way meaning distinction of PTM occurs within a sentence whereas the two-way meaning distinction of PrTM is an inter-sentential phenomenon. Nevertheless, a closer inspection reveals that 
they can be analyzed in a parallel manner. Such a unified treatment should be able to capture both of the tenses' undergeneralized meaning and thus incorporate an absolute as well as a relative meaning component. The proposal laid out in the previous chapters, which disentangles the absolute and the relative meaning components of PTM via outsourcing the 'real', absolute past tense meaning into a high, covert past operator $(O p-P A S T)$ while encoding relative past meaning into the actual past tense morpheme (-ed), is compatible with this objective. We therefore propose that the same mechanism can also account for the deviant behavior of embedded present tense.

Along the lines of our proposal for past tense, we suggest that present tense, too, consists of two ingredients: a covert present tense operator and a semantically active present tense morpheme (PrTM) that agrees with this operator. Syntactically, we assume that each PrTM carries an uninterpretable present feature [uPRES] to be checked by a covert present tense operator carrying the according interpretable feature [iPRES]. Semantically, we make the following assumptions for the two ingredients: Similar to our proposal for PTM, we suggest that each instance of PrTM (denoted for convenience by $-s$ in the following) encodes simultaneity with respect to its respective local evaluation time and thus functions as the relative meaning component of present tense:

$$
\llbracket-\mathrm{s} \rrbracket=\left[\lambda t . \lambda P . \exists t^{\prime} . t^{\prime} \text { o } t \& P\left(t^{\prime}\right)\right]
$$

Different from our account of past tense, we propose that the high, covert present tense operator $(O P$-PRES) fulfills a dual role: It establishes reference to both the local evaluation time, $t^{*}$, and to $t_{u}$. Accordingly, we take its denotation to be as follows:

$$
\llbracket O p-P R E S \rrbracket=\left[\lambda t^{*} . \lambda P .\left[\exists t^{\prime} . t^{\prime} \text { o } t^{*} \& t^{\prime} \text { o } t_{u} \& P\left(t^{\prime}\right)\right]\right]
$$

As was the case with past tense, at matrix level $t^{*}$ applies to $t_{u}$ by default. If this applies (as, e.g., in (30) and (32)), then the two tense restrictions $O P$-PRES introduces coincide and simplify to a purely absolute semantics of the operator:

$$
\begin{aligned}
\llbracket O p-P R E S \rrbracket\left(t_{u}\right) & =\left[\lambda P .\left[\exists t^{\prime} . t^{\prime} \text { o } t_{u} \& t^{\prime} \text { o } t_{u} \& P\left(t^{\prime}\right)\right]\right] \\
& =\left[\lambda P . \exists t^{\prime} . t^{\prime} \text { o } t_{u} \& P\left(t^{\prime}\right)\right]
\end{aligned}
$$

Based on these assumptions, we predict a sentence like (30), which places the event unambiguously at the utterance time, to have the following interpretation:

(30) John is running.
a. [Op-PRES $[$ [iPRES] John [be-s [uPRES] running ]]
$\exists t^{\prime}$ о $t_{u} \quad \exists t^{2}$ o $t^{\prime}$
b. $\exists t^{\prime}$ o $t_{u} \&\left[\exists t^{2}\right.$ o $t^{\prime} \&$ be-running(John, $\left.\left.t^{2}\right)\right]$ 
c. The utterance time $t_{u}$ is included in the time of John's running event.

Whereas the underspecified semantics of present tense does not have an effect on the interpretation of simple present-tensed sentences, it correctly predicts the facts observed in (26), as it interacts differently with different embedding environments. Let us first consider a present-under-future embedding (cf. (26a)).

As already stated in our discussion of (16), we assume in line with many others (e.g., Abusch 1988; Ogihara 1996; Condoravdi 2002) that will is the tenseless futureshifting modal woll in its present-tensed form (which for us is encoded as woll + [uPRES]).

$$
\llbracket \text { woll }_{[\mathrm{uPRES}]} \rrbracket=\left[\lambda t \cdot \lambda P . \exists t^{\prime} \cdot t^{\prime}>t \& P\left(t^{\prime}\right)\right]
$$

We, again, follow Zeijlstra (2012) in that the covert operator carrying [iPRES] must c-command the highest instance of [UPRES] at the lowest position where this is syntactically and semantically possible. Consequently, Op-PRES must take scope over will in (26a), leading to the operator's being valued against $t_{u}$ again, and turning it into a purely absolute operator (as in (30)). Hence, in future-embedded environments, the dual effect of $O p$-PRES remains invisible.

(32) John will say Mary is pregnant.

a. [ Op-PRES [iPRES] $_{\text {[ John [ woll }}$ [uPRES] say-s $_{\text {[uPRES] }}$ [ Mary [ be-s [uPRES]

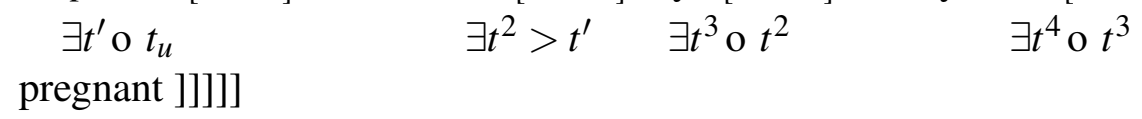

b. $\exists t^{\prime}$ o $t_{u} \&\left[\exists t^{2}>t^{\prime} . \exists t^{3}\right.$ o $t^{2} \& \operatorname{say}\left(\mathrm{John}, t^{3},\left[\exists t^{4} \mathrm{o} t^{3}\right.\right.$ \& be-pregnant(Mary, $\left.\left.\left.\left.t^{4}\right)\right]\right)\right]$

c. John's saying happens strictly after the utterance time $t_{u}$ and Mary's pregnancy overlaps the time of John's saying.

The same assumptions make the dual effect of $O p$-PRES become visible in present-under-past embeddings (cf. (26b)). Here, Zeijlstra's 2012 constraint places $O p$-PRES in the embedded clause, resulting in $O p$-PRES's relative tense parameter's being valued against the local evaluation time which is provided by the matrix past. As a result, we, correctly, predict present-under-past embeddings to have the following semantics:

(33) John said Mary is pregnant.

$$
\begin{aligned}
& \text { a. [ } O p-P A S T_{[\mathrm{iPAST}]}\left[\mathrm { John } \left[\mathrm { say } _ { \text { ed } } \text { [uPAST] } \left[O p-P R E S_{[\mathrm{iPRES}]}\right.\right.\right. \text { [ Mary [ } \\
& \exists t^{\prime}<t_{u} \quad \exists t^{2} \leq t^{\prime} \quad \exists t^{\prime \prime} .\left[t^{\prime \prime} \text { o } t^{2} \& t^{\prime \prime} \text { o } t_{u}\right] \\
& \text { be-s[uPRES] pregnant ]]]]]] } \\
& \exists t^{3} \text { o } t^{\prime \prime}
\end{aligned}
$$


Towards a New Explanation of Sequence of Tense

b. $\exists t^{\prime}<t_{u} \&\left[\exists t^{2} \leq t^{\prime} \& \operatorname{say}\left(\mathrm{John}, t^{2},\left[\left[\exists t^{\prime \prime} .\left[t^{\prime \prime}\right.\right.\right.\right.\right.$ o $t^{2} \& t^{\prime \prime}$ o $\left.t_{u}\right] \&\left[\exists t^{3} \mathrm{o} t^{\prime \prime} \&\right.$ be-pregnant(Mary, $\left.\left.\left.\left.t^{3}\right)\right]\right]\right]$

c. John's saying happens strictly before the utterance time $t_{u}$ and Mary's pregnancy overlaps the time of John's saying and the utterance time.

In sum, this approach to present tense systematically assigns either a sim or a d-a reading to embedded PrTM (i.e., a sim reading when the matrix clause is a present/future; a d-a reading when it is a past), while keeping the intuitive meaning of unembedded present tense intact. As for our past proposal, the assumption of two semantically active meaning components (Op-PRES and $-s)$, again, opens up space for cross-linguistic variation.

\section{Conclusion}

In this paper, we provide a novel SoT-account which avoids ambiguity at the level of LF while at the same time retaining the possibility for both a simultaneous and a backward-shifted reading independent of the temporal profile of the embedded predicates. The two readings are licensed via the weak precedence relation introduced by the semantic meaning component of past tense morphology (i.e. 'no later than' rather than 'strictly earlier than' semantics). We show that this approach can deal with the same challenges as other SoT approaches and has certain additional advantages as well, such as the possibility to account for cross-linguistic variation and its extensibility to present tense.

\section{References}

Abusch, D. 1988. Sequence of tense, intensionality and scope. In Proceedings of the 7th West Coast Conference on Formal Linguistics, 1-14. Stanford, CA: CSLI.

Abusch, D. 1997. Sequence of tense and temporal de re. Linguistics and Philosophy 20(1). 1-50.

Altshuler, D. 2016. Events, States and Times: An essay on narrative discourse in English. Berlin: de Gruyter.

Altshuler, D. \& R. Schwarzschild. 2012. Moment of change, cessation implicatures and simultaneous readings. In V. Homer E. Chemla \& G. Winterstein (eds.), Proceedings of Sinn und Bedeutung, vol. 17, 45-62. Paris: ENS.

Arnold, D. 2007. Non-restrictive relatives are not orphans. Journal of Linguistics 43(2). 271-309.

Borsley, R. D. 1992. More on the difference between English restrictive and nonrestrictive relative clauses. Journal of Linguistics 28(1). 139-148. 
Condoravdi, C. 2002. Temporal interpretations of modals: modals for the present and modals for the past. In B.Z. Clark \& S. Kaufmann D. Beaver, L.D. Casillas Martínez (ed.), The Construction of Meaning, 59-87. Stanford, CA: CSLI.

Demirdache, H. 1991. Resumptive chains in restrictive relatives, appositives, and dislocation structures: MIT, $\mathrm{PhD}$ dissertation.

Enç, M. 1987. Anchoring conditions for tense. Linguistic Inquiry 18. 633-657.

Fabb, N. 1990. The difference between English restrictive and nonrestrictive relative clauses. Journal of Linguistics 26(1). 57-77.

Grønn, A. \& A. von Stechow. 2010. Complement tense in contrast: the SOT parameter in Russian and English. Oslo Studies in Language 2(1). 109-153.

Heim, I. 1994. Comments on Abusch's theory of tense. Ellipsis, tense and questions 143-170.

Ippolito, M. 2013. Subjunctive Conditionals: A Linguistic Analysis. Cambridge: MIT P.

Khomitsevich, O. 2007. Dependencies across phases: From sequence of tense to restrictions on movement: Utrecht University, PhD dissertation.

Klecha, P. 2016. Modality and embedded temporal operators. Semantics and Pragmatics 9. 9-1.

Klein, W. 1994. Time in Language: Germanic Linguistics. London: Routledge.

Kratzer, A. 1998. More structural analogies between pronouns and tenses. In Proceedings of SALT VIII. (Cornell Working Papers in Linguistics), vol. 8, 92-110.

Kusumoto, K. 1999. Tense in embedded contexts: UMass Amherst dissertation.

Ogihara, T. 1989. Temporal reference in English and Japanese: University of Texas, $\mathrm{PhD}$ dissertation.

Ogihara, T. 1995. The semantics of tense in embedded clauses. Linguistic Inquiry 663-679.

Ogihara, T. 1996. Tense, Scope and Attitude Ascription. Dordrecht, NL: Kluwer.

Ogihara, T. \& Y. Sharvit. 2012. Embedded tenses. In R. Binnick (ed.), Handbook of Tense and Aspect, Oxford: Oxford UP.

Reichenbach, H. 1947. The tenses of verbs. In Elements of Symbolic Logic, 287-298. New York: Macmillan.

Ross, J. R. 1967. Constraints on variables in syntax: MIT, PhD dissertation.

Safir, K. 1986. Relative clauses in a theory of binding and levels. Linguistic Inquiry 663-689.

von Stechow, A. 1995. On the proper treatment of tense. In Proceedings of salt $v$. (cornell working papers in linguistics), vol. 5, 362-386.

von Stechow, A. 2002. Temporal prepositional phrases with quantifiers: Some additions to Pratt and Francez (2001). Linguistics and Philosophy 25(5). 755800 . 
Towards a New Explanation of Sequence of Tense

von Stechow, A. 2003. Feature deletion under semantic binding: Tense, person, and mood under verbal quantifiers. In Proceedings of NELS 33, vol. 33, 379-404. von Stechow, A. 2005. Semantisches und morphologisches Tempus: Zur temporalen Orientierung von Einstellungen und Modalen. Neue Beiträge zur Germanistik 4(2). 9-54.

von Stechow, A. 2006. Types of iF/uF Agreement. Ms. University of Tuebingen. Stowell, T. 2007. The syntactic expression of tense. Lingua 117(2). 437-463.

Zeijlstra, H. 2012. There is only one way to agree. The Linguistic Review 29. 491-539.

\author{
Carina Kauf \\ Käte-Hamburger-Weg 3 \\ 37073 Göttingen \\ Germany \\ carina.kauf@uni-goettingen.de
}

\author{
Hedde Zeijlstra \\ Käte-Hamburger-Weg 3 \\ 37073 Göttingen \\ Germany \\ hzeijls@uni-goettingen.de
}

